\title{
Revista Claudia: a discursivização da mulher e do casamento durante a segunda metade do século $\mathrm{xx}$
}

\author{
Revista Cláudia: the discursivization of women and marriage during the second \\ half of the twentieth century
}

\author{
Ceres Ferreira Carneiro ${ }^{1}$
}

\begin{abstract}
RESUMO
Trazemos uma reflexão sobre como a imprensa feminina brasileira contribuiu para a homogeneização de sentidos sobre o feminino e sobre o casamento, durante o século XX, com destaque para as respostas dadas por Carmen da Silva às cartas enviadas ao "consultório sentimental" da revista feminina Claudia.

Palavras-chave: Revista feminina. Análise do Discurso. Casamento.
\end{abstract}

\begin{abstract}
We bring a reflection on how the Brazilian women's press contributed to the homogenization of meanings over the feminine as well marriage during the twentieth century, especially the answers given by Carmen da Silva to the letters sent to the "sentimental consulting room" of the women's magazine Claudia.
\end{abstract}

Keywords: Women's press. Discourse Analysis. Marriage.

Neste artigo, trago um recorte da minha tese, cujo principal objetivo foi, à luz da Análise do Discurso de linha francesa ${ }^{2}$, analisar os discursos materializados nas cartas (e em suas respostas) publicadas nos "consultórios sentimentais" da revista feminina

\footnotetext{
${ }^{1}$ Graduada em Turismo (Estácio de Sá) e em Letras (Universidade Estadual do Rio de Janeiro), Mestra em Desenvolvimento Regional e Meio Ambiente (Universidade Federal de Rondônia), Doutora em Estudos da Linguagem (Universidade Federal Fluminense). Atuou como docente, por mais de 20 anos, em diversas Escolas e Universidades, no Rio de Janeiro, em Curitiba e em Rondônia, tendo, por último, atuado como professora substituta no Colégio de Aplicação da UFRJ. Atualmente, vinculada ao Programa de Pós-Doutorado de Estudos de Linguagem da UFF, desenvolve pesquisa sobre os sentidos in-esperados nos discursos religiosos de mulheres sobre o casamento. E-mail: cerescarneiro@gmail.com.
}

2 Esclarecemos que nosso trabalho foi pautado nos estudos desenvolvidos, no Brasil, a partir das obras de Michel Pêcheux publicadas, na França, entre as décadas de 1960 e 1980. 
Claudia (nas últimas seis décadas), considerando os efeitos de sentido produzidos historicamente (PÊCHEUX, [1969] 2014) acerca dos triângulos amorosos e dos sujeitos neles envolvidos em suas diferentes condições de produção.

Propomo-nos, aqui, a refletir sobre como os dizeres em circulação nas revistas femininas marcam condutas praticadas em um determinado momento histórico e favorecem a circulação de saberes a respeito do feminino. Para tanto, discorreremos sobre as primeiras publicações destinadas ao gênero feminino no Brasil e sobre a mídia revista para, então, adentrarmos na revista Claudia, com destaque para a colunista e conselheira sentimental Carmen da Silva, observando, especificamente, a constituição dos sentidos e os processos de significação presentes no dizer sobre relações amorosas a três a partir de treze sequências discursivas (doravante SD) selecionadas de respostas suas dadas a cartas sentimentais publicadas na segunda metade do século XX.

As cartas, inseridas em uma seção da revista feminina Claudia, constituem um arquivo e, como tal, dizem muito da formação ideológica em que a revista está filiada. Claudia, vale ressaltar, é uma revista feminina e não feminista, o que já nos antecipa que seus dizeres partem de um lugar onde a imagem de mulher é a de feminina, em oposição ao que é do masculino. Escolhemos a revista Claudia porque, além de destinada ao público feminino, nessa segmentação, é a mais antiga ainda em circulação no Brasil (desde 1961).

Entendemos que Claudia, sendo uma revista feminina, reflete as mudanças sociais pelas quais as mulheres passaram porque o que é publicado na e pela mídia é atravessado por uma ideologia e é determinado "pelas relações de força que atuam no conjunto da sociedade" (CAZARIN e MENEZES, 2014, p. 114), o que nos permite identificar quais sentidos lá ressoam e são (re)significados. Ao determinarem "o que pode e o que não pode ser dito em seus diferentes espaços, em cada instância de circulação" (DELA-SILVA e DIAS, 2015, p. 131), as revistas influenciam e incentivam determinadas falas e fazeres, possibilitando, assim, "a constituição de um "nós" (VENTURINI, 2012, p. 300), afinal, pretendem ser, de alguma forma, "porta-vozes" das leitoras, um "guia" de comportamento, formando "gostos, opiniões, padrões de consumo 
e de conduta" (BASSANEZI, 1996, p. 15). Logo, sujeitos-jornalistas e sujeitos-leitores ${ }^{3}$ de Claudia fazem circular sentidos sobre a mulher e, em nossa especificidade, sobre o casamento pelos quais são modelados dentro de uma determinada formação social. E sobre isso trataremos...

\section{A mídia revista}

A revista, ao lado da TV, do rádio, do jornal, entre outros, se configura como uma mídia, responsável por fazer circular informações a um grande número de pessoas. Segundo Mello (2013), a mídia revista é segmentada por temas e sua periodicidade pode ser semanal, quinzenal ou mensal; possui uma boa qualidade de impressão: fotos coloridas, material resistente, o que permite o manuseio de um mesmo exemplar por diversas pessoas e por muito tempo após sua publicação. Por não ser diária e nem lida, normalmente, às pressas, as revistas exigem matérias mais elaboradas que não se tornem desinteressantes pela falta do ineditismo. Ali (2009) complementa, dizendo ser a revista

um meio de comunicação portátil, fácil de usar e oferece grande quantidade de informação por um custo pequeno. Entra na nossa casa, amplia nosso conhecimento, nos ajuda a refletir sobre nós mesmos e, principalmente, nos dá referências para formarmos nossa opinião. [...] É encadernada em papel encorpado e de qualidade, é colecionada, guardada, são bonitas, as ilustrações e as fotos têm cores vibrantes, tipografia elaborada e design elegante, agradável de tocar e folhear (p. 3).

A autora chama a atenção para o fato de a beleza da revista e a sua encadernação favorecerem o seu manuseio constante e também para o fato de as revistas serem guardadas, colecionadas. Ao colecionar uma revista, entendemos, o leitor está organizando um arquivo, "documentos pertinentes e disponíveis sobre uma questão"

\footnotetext{
${ }^{3}$ Ao longo do Artigo, sempre nos referiremos a quem produz discurso como "sujeito", porque pela perspectiva da Análise do Discurso a qual somos filiados, todo indivíduo é interpelado pela ideologia e afetado pelo inconsciente, tornando-se, então, sujeito.
} 
(PÊEHEUX, 1997, p. 57) ${ }^{4}$ de seu interesse, o que leva à assiduidade da aquisição da revista, a um apego por ela e a um retorno esporádico a ela.

Segundo Vidutto (2010), a palavra revista tem sua origem no vocábulo inglês review, que estampou (e estampa) várias revistas desde o século XVIII, ou do vocábulo, também inglês, magazine, importado de Magazines (Lojas de Departamento), fazendo uma analogia à venda de "um pouco de tudo" (característica desse tipo de comércio). Ali (2009) diz que a palavra 'magazine' tem sua origem na palavra árabe al-mahazen, que designa armazém e também traz a ideia de diversidade. No Brasil, a revista "Armazém de Novellas Escolhidas”, de 1851, é um exemplo da relação entre os termos (VIDUTTO, 2010).

As revistas, entretanto, não se reduzem a abordar superficialmente sobre muitos assuntos, a serem meros informativos periódicos, tratando sobre "um pouco de tudo". Elas

vieram para ajudar na complementação da educação, serviço e interpretação dos acontecimentos. Possui menos informação no sentido clássico (as "notícias quentes") e mais informação pessoal (aquela que vai ajudar o leitor em seu cotidiano, em sua vida prática). Isso não quer dizer que as revistas não busquem exclusividade no que vão apresentar a seus leitores. Ou não façam jornalismo (SCALZO, 2004, p. 14).

O jornalismo, por outro lado, presente nas revistas femininas sofreu (e sofre) preconceitos ao ser, comumente, tratado como menor, "não sério", por se relacionar a assuntos considerados de pouca importância: moda, culinária, beleza, decoração... Segundo Portilho (2009), por exemplo, as revistas femininas discorriam sobre "novidades", amenidades, serviços e não sobre fatos, o que se esperava de um jornalismo "sério".

As revistas, entretanto, trazem indícios das mudanças sociais e interferem nelas já que são um lugar de produção de sentidos, em que posições são delineadas e alteradas de forma a garantir que o sujeito-leitor se mantenha identificado: "o leitor se identifica e se acostuma com o ‘jeito’ da sua revista, [...] tem a sensação de familiaridade” [...]. A

\footnotetext{
${ }^{4}$ Esse, conforme Pêcheux (1997), é um modo recorrente de se pensar o arquivo.
} 
revista é como uma pessoa um companheiro que está lá [...]: uma relação de um-comum, família íntima e envolvente” (ALI, 2009, p. 4). Haveria, assim, mais do que uma identificação das leitoras com os saberes que circulam na revista, haveria uma cumplicidade entre o sujeito-leitor e o sujeito-jornalista por meio das revistas, conforme poderemos atestar pelos fragmentos das respostas de Carmen da Silva apresentados mais adiante.

Ocorre que o sujeito-jornalista se apropria tanto dos saberes 'das coisas de mulher', "quanto os do senso comum - recorta, incorpora o que lhe interessa desses diferentes saberes [...], linearizando-os no fio do discurso e materializando, assim, um discurso que pretende divulgar ao leitor" (GRIGOLETTO, 2005, p. 2) e que o sujeito-leitor, ao se identificar com os saberes incorporados na revista, tende a se tornar um leitor assíduo.

Contudo, cabe observar que o sujeito-jornalista da revista, com o intuito de dizer o que é esperado pelo sujeito-leitor, tem apenas a ilusão de antecipar os efeitos de sentido que os textos, por ele escrito, produzirão. O sujeito-leitor produzirá suas próprias leituras porque sentidos aparentemente estabilizados e evidentes sempre são passíveis de se tornarem outros (INDURSKY, 2011), pois é nessa movência que o discurso se dá: e é essa movência que pretendemos apresentar.

\section{A imprensa feminina brasileira}

Temos que a imprensa foi estabelecida como uma instituição porque faz circular conhecimentos, logo, é um importante instrumento de circulação de sentidos, capaz de modelar e controlar práticas sociais (DELA-SILVA, 2008). Mas, como todo Aparelho Ideológico de Estado, ou seja, "um certo número de realidades que se apresentam ao observador de imediato sob forma de instituições distintas e especializadas: religiosos, escolar, familiar, jurídico, político, sindical, da informação (revista), cultural” (ALTHUSSER, 1974, p. 43), a mídia não é isenta e, conforme denunciam Jardim e Brandão (2014), a imprensa brasileira, desde o seu surgimento funciona como um "aparelho hegemônico do Estado, atuando como instrumento difusor da ideologia da classe dominante a que ela pertence” (p. 170).

A fim de vislumbrarmos os saberes postos em circulação nas revistas femininas brasileiras, tidos como de "interesse" das mulheres, traçamos (de forma ampla) como a 
sociedade brasileira se caracterizava entre os séculos XIX e meados do século XX, fazendo um paralelo com o surgimento das principais revistas femininas brasileiras.

Às meninas, no Brasil, foi dado o direito de frequentar a escola apenas em meados do século XVIII, durante a administração pombalina. Sob a perspectiva do patriarcado, se entendia que a "educação da agulha" bastava para garantir seu bom desempenho doméstico e o exercício do que seriam suas duas funções primordiais: ser esposa e mãe. Quando tinham acesso ao letramento, era para servir ao comércio do pai ou do marido e/ou ensinar aos filhos seus ou aos dos Senhores. Portanto, poucas mulheres liam as primeiras revistas, já que, em meados do século XIX, somente cerca de dez por cento da parcela feminina (não-escrava) era alfabetizada.

As primeiras revistas (ou jornais, como também eram chamadas) voltadas para o público feminino surgem, no Brasil, no início do século XIX. Segundo Duarte (2016), foram os "primeiros e principais veículos da produção letrada feminina, que, desde o início, se configuraram em espaços de aglutinação, divulgação e resistência" (p. 14). O Espelho Diamantino foi o primeiro periódico brasileiro dedicado às senhoras, tendo circulado entre os anos de $1827^{5}$ e 1828 , no Rio de Janeiro.

Este e outros periódicos tinham um caráter pedagógico e "revelavam a ideologia patriarcal que os dominava" (SCALZO, 2004, p. 21). Conforme nos faz lembrar Rebelo (2017), as revistas femininas, ainda hoje, se amparam em um discurso didatizante, já que funcionavam (e funcionam) como um "manual" ou "cartilha de comportamento" que dita o que pode ou deve ser feito, propiciando a circulação de "certas discursividades sobre o feminino na sociedade" (p. 06). As mulheres, imaginariamente tomadas na sociedade patriarcal, enquanto seres "dependentes" e "pouco racionais", precisariam de aconselhamentos, de direcionamentos, de "receitas" de felicidade. "Deixá-las à altura da civilização e dos seus progressos" (SCALZO, 2003, p. 28) é pressupor a sua posição de inferioridade (ignorância e desatualização) diante dos novos acontecimentos.

A imprensa feminina traz em si "um conceito definitivamente sexuado: o sexo de seu público faz parte de sua natureza. Desde que surgiu no mundo ocidental, no fim do século XVII, já trouxe a distinção às mulheres no próprio título do jornal - Lady’s

\footnotetext{
${ }^{5}$ Ano da edição da Primeira Lei de Instrução Pública. A partir de então, as meninas passaram a ter acesso ao curso primário oferecido pela escola pública.
} 
Mercury - prática a persistir até hoje" (BUITONI, 1986, p. 7). É uma imprensa que segrega, marca que aquele periódico é destinado às mulheres porque "coisas de mulheres" não seriam de interesse dos homens. Os títulos funcionariam, assim, como um comando, uma antecipação de que o periódico é só para as mulheres: $O$ Jornal das Senhoras, $O$ Correio das Damas, O Espelho das Bellas, Claudia são alguns desses exemplos.

Em meados do século XIX, foi extinto o tráfico negreiro e a monarquia se firmou como um sistema político capaz de manter a unidade nacional. $\mathrm{O}$ fim gradativo da mãode-obra escrava alterou não só a economia, mas também a sociedade brasileira. Ocorre que o proletariado europeu chegou ao Brasil para atender à defasagem de trabalhadores braçais e, em decorrência, novos hábitos, típicos da Europa, foram inseridos ao cotidiano brasileiro. As mulheres das classes altas e médias puderam ter mais contato com as artes europeias e as poucas letradas, com tempo ocioso, se dedicaram aos romances, tornando-se leitoras assíduas, o que favoreceu o surgimento de várias revistas femininas.

O Jornal das Senhoras (circulou, na Corte, entre os anos de 1852 e 1855) foi considerado o marco da revista feminina brasileira: era escrito por mulheres para leitoras mulheres. O fato de o discurso sobre as "coisas de mulher" partir de mulheres era uma novidade, pois até então cabiam aos homens discorrer sobre o comportamento feminino. Esta mudança propiciou às mulheres a ocupação de um espaço público (dominantemente masculino) capaz de lhes dar voz. O Jornal das Senhoras trazia no edital que pretendia "cooperar com todas as forças para o melhoramento social e a emancipação da mulher" (apud COELHO e DAVID, 2003, p. 7). Vários homens escreveram para a redação manifestando seu incômodo com os teores, supostamente, feministas da revista. A fundadora, Georgina Pires, e a gerente, Dolores Diniz, se restringiram a garantir o anonimato dos artigos mais polêmicos.

De lá para cá, muitas revistas femininas surgiram e desapareceram: Sexo Feminino (fim do século XIX); A Família (fim do século XIX); A Estação (fim do século XIX); A Cigarra (primeiras décadas do século XX); Frou-Frou (início do século XX); Revista Feminina (início do século XX), citada por Buitoni (1986) como a mais inovadora da época porque sua estrutura comercial inspirou o surgimento de outras revistas da 
mesma segmentação; O Jornal das Moças (primeira metade do século XX); Realidade (década de 1960)6.

Apesar do discurso didatizante presente nas revistas femininas, que enfatizava a domesticidade da mulher burguesa e as projetava como dóceis cuidadoras do lar, do marido e dos filhos, "o espaço discursivo da imprensa feminina do final do século XIX, em sua heterogeneidade, construía discursos atravessados pelas teses de modernização do país e da necessária reconfiguração dos papéis sociais femininos nessas transformações" (FERREIRA, 2007, p. 5). E, de forma a atender a esses novos papéis assumidos pelas mulheres, embasadas no desejo de deslocamento da casa para as ruas (e que previam, inclusive a luta pelo direito ao voto), as revistas foram se moldando, trazendo, em seu bojo, novas ideias sem, com isso, se distanciar, a contento, de um modelo social alicerçado na dominação masculina.

A revista Sexo Feminino, lançada timidamente em Campanha, interior do estado de Minas Gerais, em 1873, logo mudou seu endereço para o Rio de Janeiro. Emancipada para época, era contrária à subserviência da mulher ao marido e apoiava a escolaridade das mulheres.

O jornal A Família (1888-1898) foi fundado na cidade de São Paulo, migrando um ano depois para o Rio de Janeiro, por Josephina Álvares de Azevedo, irmã do escritor Álvares de Azevedo. Josephina era ferrenha defensora da emancipação feminina e da lei do divórcio, deflagrando a luta por tais causas ao torná-las temas recorrentes nas páginas de seu jornal durante os dez anos de sua existência.

A revista $A$ Estação, lançada no final do século XIX, adentrando os primeiros anos do século XX, era versão brasileira da revista alemã Modenwelt, tinha como mote a moda parisiense, inspirando as mulheres a copiarem os figurinos lá impressos e dando conselhos sobre como se vestir bem, sendo econômica. Apesar da comum futilidade dos assuntos abordados, havia uma parte da revista (especialmente feita para edição brasileira) destinada à literatura nacional e que se propunha a ocupar toda a família: foi nela que Machado de Assis publicou, em forma de folhetim, seu romance "Quincas Borba”, além de vários contos e alguns poemas.

6 A revista Realidade não é considerada uma revista feminina, entretanto, conforme explicaremos adiante, entendemos pertinente incluí-la em nosso histórico. 
A Cigarra (lançada em 1914) e Frou-Frou (lançada em 1923) não defendiam nenhuma causa feminista e se detiveram a tratar, além de assuntos entendidos pelo senso comum da época como "de mulher" (fofocas, moda, beleza), de matérias sobre cinema e esportes, sem deixar de refletir o comportamento das classes média e alta brasileiras.

A Revista Feminina (1915-1936) começou como um folheto de divulgação de produtos destinados às mulheres, vendido porta a porta. Tornou-se uma revista e premiava as mulheres que vendessem a assinatura, chegando ao patamar, até então inédito, de 20 mil exemplares por mês. Vários artigos escritos por homens, que apresentavam pseudônimo de mulher, tinham teor machista: a coluna de receita, por exemplo, intitulava-se "O menu do meu marido". Se inovou na estrutura comercial, $A$ Revista Feminina, na abordagem, se manteve estagnada.

O Jornal das Moças chama atenção porque circulou por quase 50 anos (1914 a 1960), foi o mais vendido no período e tinha circulação nacional. Oportunizava às espectadoras de radionovelas (uma "febre", no país, da primeira metade do século XX) vislumbrar as fotos dos seus ídolos. Dava dicas sobre moda, culinária, corte-e-costura, comportamento, beleza, produtos de limpeza... Difundia valores morais conservadores, consonantes com os preceitos católicos e patriarcais, valorizando a esposas-mães-donasde-casa para as quais dedicava seus conselhos, conforme podemos observar:

não há dever mais sagrado do que o da fidelidade; não basta que sejas fiel, é preciso que teu marido e todos nunca disso duvidem um instante. Deves ser modesta, mas com certa delicadeza em reserva, e deves inalteradamente prestar aos teus próprios olhos o testemunho da tua virtude (Mensagens às noivas. Jornal das Moças, $n^{\circ}$ 1894. p. 9. Rio de Janeiro, 1951 apud ALVES, CAETANO e FREITAS, 2016, p. 110).

Essa publicação pretendia manter ou chamar de volta as mulheres à família e ao lar. Se necessitassem trabalhar fora, sugeria a profissão de professora, enfermeira ou afins.

A revista Realidade, segundo Bahia (1990), foi, durante os anos de 1960, a mais representativa no mercado brasileiro e, apesar de definida como uma revista de informação geral sobre assuntos nacionais (não feminina, portanto), abordava, 
comumente, temáticas voltadas às mulheres. Em janeiro de 1967, por exemplo, foi publicada uma edição especial, denominada "a mulher brasileira hoje"7, estampando as seguintes manchetes na capa: "o que elas pensam e querem"; "confissões de uma moça livre"; "ciência: o corpo feminino"; "eu me orgulho de ser mãe solteira"; "por que a mulher é superior"; "assista a um parto até o fim". Fortemente influenciada pelo New Journalism, modelo norte-americano, primava pela liberdade criativa e produtiva dos jornalistas que adotavam o estilo literário em sua escrita (FARO, 1998).

As revistas femininas, no geral, projetavam a imagem das suas leitoras como de mulheres frágeis, "de sentimentos brandos e piedosos, assinalados pelo signo do amor e da maternidade, cujas virtudes morais devem ser resguardadas com diligência”, havendo entre elas "uma nítida recusa por assuntos relacionados à política" e um forte interesse por "poesias, histórias sentimentais, moda, vida social e cultural, etiqueta, higiene, decoração, utilidade doméstica" (CRESTANI, 2008, p. 345).

Ainda que O Jornal das Senhoras, Sexo Feminino (ambas de propriedade de professoras, diga-se) e $A$ família, de Josephina Álvares de Azevedo, tenham ousado ao abordar temáticas feministas, a imprensa feminina do século XIX e a de grande parte do século XX primavam por conteúdos fúteis, recreativos e didatizantes porque estavam, justamente, em concordância com a imagem por ela projetada das suas leitoras, que, por sua vez, se identificavam com o que liam.

Essas e outras revistas delinearam "os hábitos, as modas, os personagens de cada período, os assuntos que mobilizaram grupos de pessoas” (SCALZO, 2003, p. 16) e contribuem para que vislumbremos parte do que era entendido como "mundo feminino", e comecemos a entender as condições de produção em que Claudia surge e que a fez, no final do século XX, ser definida pela frase "independente, sem deixar de ser mulher".

\section{Claudia, "sua companheira fiel"}

Claudia, segundo Ferreira e Rêgo (2012), é a revista feminina mais antiga ainda em circulação no Brasil, a de número 1 data de outubro de 1961. A primeira edição teve

\footnotetext{
${ }^{7}$ Esta edição, após uma denúncia de autoria desconhecida, foi cassada sob a alegação de que nela havia conteúdo considerado "abusivo", "obsceno" e "ofensivo à dignidade e à honra da mulher", conforme descrito pelo editorial da edição seguinte da própria revista.
} 
oitenta e nove páginas e a periodicidade de sua publicação sempre foi mensal. Sua primeira tiragem foi de 150.000 exemplares. É líder do segmento desde sua criação.

O projeto editorial de Claudia trazia cartas de aconselhamento, horóscopo, moda, beleza, decoração, culinária, boas maneiras, contos, crônicas, cuidados com animais domésticos, sugestões de livros, educação dos filhos, encartes de moldes de roupas e reportagens informativas (REIS, 2012, s/p).

Para entendermos melhor as condições em que a revista Claudia surgiu, delineamos o que era o Brasil (e o mundo) nas décadas de 1950/60. Importantes mudanças sociais, advindas dos avanços científicos e tecnológicos ocorreram na década de 1950, conhecida como "Anos Dourados". Internacionalmente, destacamos os conflitos entre países socialistas (liderados pela antiga URSS) e capitalistas (liderados pelos EUA) e, nacionalmente, destacamos o fomento de uma indústria nacional (iniciada por Vargas e sedimentada por JK) que viria a substituir a importação de muitos produtos. Pairava entre os brasileiros a ideia de progresso e modernização: eletrodomésticos faziam a alegria das donas de casa, inclusive a televisão, cujas primeiras transmissões da América Latina chegaram pela TV Tupi, e este novo meio de comunicação, diga-se, contribuiu bastante para difundir o pensamento nacionalista. No campo das artes, Elvis Presley, nos EUA, e a Bossa Nova, no Brasil, precederam a contracultura, apresentando um novo estilo de fazer música.

Esse rápido desenvolvimento industrial ocorrido no Brasil, aliado a essa efervescência cultural da virada da década de 1950 para a de 1960, estimularam os editores a criar revistas segmentadas, inspiradas, provavelmente, no fordismo, modelo de sistema de linha de produção seccionado. Naquele período, diversas revistas surgem para atender a um determinado grupo de leitores, inclusive Claudia: "criada em 1961 com o slogan 'a revista amiga', [...] se afinava com os ideais de modernização e com a expansão do capitalismo (PORTILHO, 2009, p. 02), funcionando como mais um "manual" ou "guia de instrução" de melhor viver, no dia-a-dia, destinado às mulheres.

Destacamos que, na década de 1960, momento histórico em que Claudia surge e se consolida, estava em plena ebulição o movimento feminista na Europa e nos Estados Unidos, ainda que, no Brasil, as discussões sobre a liberdade da mulher só ganhariam 
destaque com a popularização da pílula na década de 1970, tema, aliás, discutido amplamente por Claudia já em 1968 (AZEVEDO, 2009). As mulheres, no entanto, ainda pelos anos de 1960, conquistaram alguma liberdade sexual e tiveram a minissaia como símbolo dessa mudança de paradigma. O cinema que, por meio das personagens Séverine Serizy, interpretada por Catherine Deneuve, em Belle de Jour, e Sra. Robinson, interpretada por Ann Bancroft, em The Graduate, ambos os filmes de 1967, ratificou essa liberdade sexual que começava a ser também uma prerrogativa do feminino. Mas, embora os movimentos feministas dos anos de 1960 tenham contrariado o funcionamento ideológico patriarcal, ele continuava

a produzir o efeito desejado, pois o máximo alcançado pela ideologia feminista foi o de agregar novas funções para as mulheres, mas não o de eliminar o processo de naturalização da maternidade. As mulheres continuam sendo as responsáveis pelo desenvolvimento das atividades domésticas e pela educação dos filhos, cabendo aos homens quando muito uma ajuda, na maioria das vezes, não significativa (MAGALHÃES, 2017, p. 8)

De qualquer forma, a "Segunda Onda Feminista" marcou profundamente as primeiras décadas de Claudia, as mulheres reivindicavam a igualdade de gêneros, o que representava uma significativa mudança comportamental em jogo, e a revista precisava acompanhá-la. Ponha-se no bojo a aprovação da lei do divórcio (que, apesar de ocorrer apenas em 1977, já era um tema debatido nos anos 1960), que alterou a organização familiar, permitindo aos desquitados um novo casamento oficial.

Entretanto, essa projeção de uma nova imagem de mulher não impediu Claudia de publicar dizeres inseridos ainda em uma formação discursiva católica e patriarcal, cuja castidade da moça era premissa necessária para que pudesse assumir a posição de boa-esposa, conforme podemos observar nesse fragmento que, segundo publicado em dois sites $^{\mathcal{B}}$, foi publicado na revista Claudia, em 1962: "a mulher deve estar ciente de que dificilmente um homem pode perdoar uma mulher por não ter resistido às

\footnotetext{
8 - sitedecuriosidades.com/curiosidade/revistas-femininas-nos-anos-50-e-60-a-mulher-no-mundo-machista.html - revistaprosaversoearte.com/mulher-no-mundo-machista-as-revistas-femininas-nos-anos-50-e-60/
} 
experiências pré-nupciais, mostrando que era perfeita e única, exatamente como ele a idealizara" (MIRANDA, s/a, s/p).

As condições, conforme verificamos, em que os discursos foram produzidos em Claudia, são imprescindíveis para entendermos o processo de discursivização da mulher e do casamento pela revista, já que as cartas não são descoladas dessas condições, muito pelo contrário: as mulheres mudaram e as revistas precisaram se reestruturar. Claudia não tratou apenas "de assuntos políticos e sociais", deu “enfoque, mais liberal, a temas recorrentes antes tratados de forma conservadora" (PORTILHO, 2009, p. 11) para acompanhar essa mulher que foi projetada para fora das fronteiras do lar. Mas, ressaltamos que essa migração da casa para as ruas se deu lentamente e a identificação de sujeitos-leitoras e sujeitos-jornalistas com saberes que circulavam sobre o feminino ainda seguiam embasados na hierarquia de gêneros, logo, filiados a uma rede de memória fundada no patriarcado. Assim, o discurso produzido por Claudia foi (e é) um discurso marcado pela contradição, pois precisa enaltecer "a liberdade, o trabalho, a escolarização feminina e, ao mesmo tempo", criar "um efeito discursivo que não deixe as mulheres esquecerem que seu lugar primordial é a casa, que seu espaço fundante é o da família" (MAGALHÃES, 2005, p. 42).

O primeiro editorial apresentava a revista tendo como imagem de si uma "amiga íntima”, "companheira fiel" e útil, cuja missão era dar sugestões de decoração, receitas e elegância. A revista nasceu para atender às mulheres casadas, de classe média, entre trinta e cinquenta anos de idade (BITTELBRUN, 2009), 'do lar', cujos interesses, supunham-se, restringiam-se aos previstos naquele primeiro editorial:

Você tem em suas mãos o primeiro número de uma revista que pretende desempenhar um papel muito importante na sua vida futura! CLAUDIA foi criada para servi-la. Foi criada para ajudá-la a enfrentar realisticamente os problemas de todos os dias. CLAUDIA lhe apresentará mensalmente idéias para a decoração de seu lar, receitas para deliciar a sua família, sugestões para mantê-la sempre elegante e atraente. Mas o importante é a forma como isto será feito. Antes de mais nada, CLAUDIA deverá ser útil para você. Deverá tornar-se sua amiga íntima. E estará sempre às suas ordens para lhe proporcionar tôdas as informações e novidades que você espera há tanto tempo, numa só revista, simpática, completa e moderna. Seja benvinda, pois, às páginas de CLAUDIA. Temos certeza de que ela será sua companheira fiel nos anos vindouros (Revista Claudia. Ano 1, número 1. Outubro de 1961 apud MOURA, s/a, s/p) (grifo nosso). 
Nesse parágrafo, destacamos algumas sequências discursivas que merecem nossa análise. O verbo criar ("foi criada”) nos remete ao substantivo criação, largamente empregado para ser referir à prole (criação de filhos), mantendo o efeito de familiaridade comentado anteriormente: Claudia "foi criada para" servir as mulheres, tal qual as mulheres estão a serviço do lar. Os editores pretendem ter domínio sobre o destino de Claudia, projetando o uso que suas leitoras deverão dar a ela: servi-la, ajudá-la, ser útil, ser sua companheira fiel. Claudia, por sua vez, é subserviente e "deverá" atender às leitoras em uma relação unilateral. A revista é personificada: uma amiga simpática e moderna. As palavras "sempre", "tôdas", "completa" e "certeza", como uma hipérbole, marcam um autoritarismo, uma pretensão de quem escreve de ser 'dono da verdade' e da onipotência e onipresença da revista na vida das leitoras.

Segundo o blog Emfechamento9 (2012), ao ser apresentada como a "revista amiga", criou a tal ponto "uma relação de confiabilidade e cumplicidade" com a leitora que, nas cartas enviadas à revista, surgiam expressões como "Amiga Claudia" e "Querida Claudia". Houve um processo de personificação da coisa em que "o espaço privilegiado de publicação das cartas funcionaria como atestado de fidelidade entre 'amigas" (AZEVEDO, 2009, p. 143).

O nome dado à revista, segundo Nogueira (2003), é o nome que Victor Civita (fundador da editora Abril) e sua esposa Sylvana dariam à filha que nunca tiveram. $\mathrm{O}$ nome Claudia, descumprindo a norma culta de acentuação da Língua Portuguesa, é grafado sem acento. Ao dar um nome que seria da filha à revista, há um efeito de familiaridade, criou-se um elo outro, uma relação afetiva entre o fundador da editora Abril e sua esposa, com a revista, estendido, posteriormente ao filho, Roberto, que os sucedeu na direção do Grupo. A promessa de que Claudia será "sua companheira fiel" nos anos vindouros, trazida na primeira edição, também projeta uma imagem afetiva, retomando sentidos estabilizados de que amigas (como filhos) são para sempre.

Ao longo de sua existência, Claudia se subdividiu, dando origem ("crias") a outras revistas, se fragmentando para atender aos principais interesses da mulher (ou

\footnotetext{
${ }_{9}$ O Emfechamento é um blog criado pela comunicadora social Marília Reis, "no começo de 2011, com a ideia de ser um espaço para ver e discutir editoração, design, comunicação e cultura." emfechamento.com.br/2012/03/historia-darevistaclaudia.html\#
} 
entendidos como tal), a partir da imagem projetada pela revista do sujeito-leitora de Claudia: Casa Claudia, Claudia Cozinha, Claudia Bebê, Claudia Moda e Claudia Noivas $^{10}$. Apesar das diferentes condições de produção (contextos sócio históricos e ideológicos) dos discursos materializados em Claudia, ao longo dos anos, podemos observar que as "novas" revistas têm temáticas similares às das primeiras edições, cuja imagem da mulher leitora era a de "rainha do lar". Assim, parece-nos que imagem de mulher moderna que Claudia tem da sua leitora não se descolou da imagem da mulher boa-mãe-esposa-dona-de-casa. A "revista feminina sempre fala de moda, beleza, casa, amor... O que muda é a dosagem de cada um deles, [...] é a visão histórica a partir da qual cada um desses temas vai ser exposto..." (MIRA, 2001, p. 59). As 'coisas de mulher' são as mesmas, mas deixaram de ser temáticas exclusivas e deram espaço para que outras surgissem. Dizeres sobre as 'coisas de mulher' foram reduzidos, mas não foram apagados.

Retomamos a frase "independente, sem deixar de ser mulher", lema dado à revista no final do século XX, para ratificar esse já-lá de que ser mulher perpassa pela dependência do homem, seja ela emocional ou financeira. Houve um movimento de repetibilidade que permitiu aos saberes originários em uma determinada rede de formulações a ela retornarem (INDURSKY, 2013). Mulher independente deixa de ser feminina, bela, sensual, delicada, de ter atrativos, mas Claudia vai te ensinar a ser ambas, a encontrar um ponto de interseção entre a feminilidade e a independência. Uma imagem da mulher 'boa esposa' estaria, assim, fornecendo "ingredientes que foram retomados em diferentes formas históricas [...] sob a forma” (PÊECHEUX e FUCHS, [1975] 2014, p. 165) de mulher independente. Ao dizer que a mulher independente corre o risco de perder a feminilidade, ela recupera um já-dito que vincula a feminilidade à ocupação do espaço doméstico: "incentiva-se a profissionalização da mulher [...], mas acentua-se o papel de cuidadora da casa e da alimentação da família” (BUITONI, 1986, p. 72).

Segundo Célia Pardi (Abril Institucional 50 anos apud ANTUNES, 2016), exdiretora de redação da revista, Claudia fez sucessivas adaptações para atender ao

\footnotetext{
${ }^{10}$ Ressaltamos que todas essas segmentações de Claudia foram, paulatinamente, saindo de circulação: Casa Claudia foi a última a sucumbir em 2018.
} 
público em transformação: "era a revista de uma mulher casada e santa e, nos anos 90, esse não era mais o sonho de ninguém" (p. 69). Essas transformações, entretanto, mantiveram a imagem que a revista faz da mulher independente como sendo uma nãomulher ou uma mulher masculinizada.

A revista Claudia, das suas primeiras edições até o ano de 2016, trouxe uma seção destinada ao aconselhamento sentimental, o "consultório sentimental": o conselho dado às leitoras sobre seus problemas pessoais, assim, compuseram a revista por 66 anos. Dentre os muitos profissionais encarregados de responderem as cartas, supostamente enviadas pelas leitoras, destacamos a psicóloga e jornalista Carmen da Silva, a conselheira mais reverenciada da revista Claudia, que foi colunista da revista e assinou as respostas dadas às cartas sentimentais de 1963 até a sua morte em 1985. Para melhor compreendermos como os discursos sobre o feminino e o casamento foram constituídos, formulados e postos em circulação pela revista Claudia, discorremos sobre a emblemática Carmen da Silva e analisamos discursivamente algumas sequências recortadas das respostas dadas pela jornalista. Entendemos ter o sucesso de Carmen a frente do "consultório sentimental" de Claudia se dado devido à identificação dos sujeitos-leitores com os seus dizeres postos em circulação nas páginas da revista: de alguma forma, a partir da antecipação de qual(is) imagem(ns) de mulher e do casamento são projetadas por suas leitoras, Carmen disse o que elas queriam ler.

\section{Carmen da Silva ${ }^{11}:$ conselhos sobre casamento}

Carmen da Silva, conforme já mencionado, teve uma formidável participação à frente do "consultório sentimental" de Claudia. Como feminista assumida e importante referência do feminismo, tendia, em seu dizer, não incentivar o conformismo, mas estimular a ação das consulentes perante as relações afetivas ditas infelizes. Subverteu o formato impessoal das respostas dadas às cartas sentimentais, criando uma aproximação com a consulente, marcada por adjetivos carinhosos, votos de boa sorte e provocações.

\footnotetext{
11 Observamos que, em diferentes espaços, o nome da colunista ora aparece grafado no final com "m", ora com " $\mathrm{n}$ ". Optamos pelo uso do "n" porque é assim que assinava as respostas dadas às cartas do "consultório sentimental".
} 
Segundo Azevedo (2009), Carmen "projetou-se estrategicamente para o movimento feminista, [...] tornando-se uma porta-voz de certo tipo de feminismo na revista Claudia" (p. 41), onde atuou por 22 anos ininterruptos. Das cartas pessoais que lia, tirava inspiração para seus artigos de "A arte de ser mulher", criando um diálogo entre as seções. Azevedo (2009) complementa, ao dizer que Carmen fez magistralmente "da profissão um palanque para suas ideias" (2009, p. 41). Assinou a coluna "A arte de ser mulher" e respondeu às cartas enviadas ao "consultório sentimental" de 1963 até a sua morte, em 1985, dias após ter se sentido mal durante uma conferência sobre jornalismo e feminismo, em Resende (interior do estado do Rio de Janeiro), aos 65 anos de idade. Lá, disse a última das suas muitas frases impactantes: "a discussão sobre a mulher ampliou-se: hoje ela interessa também aos homens, aos inteligentes, é claro" (apud HANCIAU, s/a, s/p).

Foi contratada por Claudia justamente para atender às mudanças sociais que punham a mulher em novas posições. Segundo o redator-chefe da época, Thomaz Corrêa (1994), eles precisavam de

alguém que mostrasse para nossas leitoras que a mulher precisava se preparar para uma nova posição na vida, que os costumes estavam mudando, e que a mulher tinha que se conscientizar de que sua situação era igual à do homem, ao lado do homem, fosse ela uma dona-de-casa, ou uma profissional em qualquer atividade (p. 5).

Podemos entender que Carmen foi um acontecimento discursivo trazido à cena por Claudia. Todo discurso traz em seu funcionamento a possibilidade de atualizar, ressignificar, deslocar sentidos regularizados, assim, em sua 'fala', Carmen que, por duas décadas, esteve à frente de duas colunas da revista,

pode desmanchar essa "regularização" e produzir retrospectivamente uma outra série sob a primeira, desmascarar o aparecimento de uma nova série que não estava constituída enquanto tal e que é assim o produto do acontecimento; o acontecimento, no caso, desloca e desregula os implícitos associados ao sistema de regularização anterior (PÊCHEUX, 1999, p.53). 
Sua picardia, as "broncas" dadas às leitoras, sua irreverência e os tabus que rompia a projetavam, a lançavam "na vida privada [...] sob a forma de espetáculo" (NORA, 1976, p. 183). Ela não era uma das colunistas, mas a colunista que criava polêmica: o seu jeito de dizer reconfigurou, assim, o jeito de dizer da época, pois Carmen transformava as cenas cotidianas em enredo, dando a elas a aparência de não-repetição, de algo inesperado e intrigante (SODRÉ, 1983).

Em "A arte de amar", tratou "das angústias e das conquistas femininas, dos problemas e das batalhas das mulheres por igualdade de gênero" (AZEVEDO, 2009, p. 41), enfrentando, para isso, inclusive, questões tidas como tabus. Carmen achava o nome da coluna "horrorosamente piegas" (AZEVEDO, 2009, p. 56), mas reconhecia a importância dela para a difusão de suas ideias. Estava certa: o sucesso à frente da coluna foi tamanho que Corrêa (1994) disse, "termina com ela a seção 'A Arte de Ser Mulher'. Não se substitui uma Carmen da Silva. Ela foi importante demais" (p. 5).

Carmen começou escrevendo para o 'consultório' de Claudia logo que entrou para a revista, em 1963, e, já nos primeiros anos, tentou transformar o "consultório sentimental" em "consultório de orientação psicológica" (SILVA, 1967, p. 86). Tal diferença, segundo ela, dizia respeito ao modo de focar e responder às cartas que passaram a ser examinadas pelos "antecedentes e pormenores dos casos [...]. Meu propósito é despertar-lhe o maior grau de consciência de si mesmo no mundo" (SILVA, 1967, p. 86). Vale ressaltar que os assuntos tabus não eram, comumente, abordados com amigos e familiares, durante as décadas de 1960/70, porque podiam causar constrangimentos e críticas severas, por isso, a importância de uma seção da revista que pudesse aconselhar às leitoras sobre suas intimidades.

A atuação de Carmen trouxe repercussões, conforme podemos atestar por esse episódio narrado no site dedicado a Carmen da Silva (HANCIAU, s/a, s/p):

em 1967, durante conferência em Goiânia, um bando de maridos indignados com seus posicionamentos (ela lotava salas de norte a sul do Brasil) ameaçou agredila (conforme artigo de seu conterrâneo, o escritor Renato Modernell, publicado em Claudia, outubro de 1990). Decide então tirar licença permanente de porte de armas, no Serviço de Armas, Munições e Explosivos. 
O fato de os maridos se reunirem para agredir Carmen, porque suas esposas estavam mudando suas condutas por influência dela, revela o machismo em nossa formação social. O termo "bando" parece-nos bem adequado se considerarmos a brutalidade do episódio. Os homens estavam incomodados e isso sinaliza uma mudança das posições das mulheres.

Carmen atestou a veracidade das cartas e disse, em 1967, que já havia lido cerca de quinze mil cartas enviadas às revistas femininas nas quais trabalhou. Recebia uma média de quatrocentas e cinquenta (450) cartas, por mês, cujo principal teor era o conflito matrimonial: adultérios, brigas, indiferenças do marido, sendo a infidelidade do homem o principal motivo pela crise no casamento. No "consultório sentimental", segundo a própria Carmen da Silva (1967), "eram prestados serviços psicológicos e apoio moral às mulheres que desejassem libertar-se do jugo machista" (p. 87).

As respostas dadas por ela às consulentes merecem um destaque de nossa parte porque foram um divisor de águas: as mulheres deixam de ser incentivadas a manter o casamento a qualquer custo e passam a ser encorajadas a não aceitar passivamente a traição do homem. Basta observarmos a SD1, fragmento da resposta dada por algum(a) conselheiro(a) antes da chegada de Carmen à revista, e as SDs 3 e 4, fragmentos de respostas dadas e assinadas por Carmen:

SD1: Suporte-o pelos seus filhos.

(Seção Claudia responde, Ano 3, nº 22, p. 05, julho de 1963.)

SD2: Acho, pois, que você deve procurar o momento oportuno para abordar o assunto com a máxima objetividade e serenidade possível. Esqueça "a megera": não lhe cabe julgá-la e, seja como for, o que está atrapalhando a união de vocês dois não é ela. É a indecisão dele.

(Seção Aqui, Carmen responde, Ano XVIII, nº 208, p. 04, fevereiro de 1979.)

SD3: Mostre claramente a seu marido que estão em jogo sentimentos humanos muito reais e profundos e por mais moderninhos que vocês sejam vivem numa cultura monogâmica que os condiciona a um casamento monogâmico.

(Seção Carmen responde, Ano XXI, nº 251, p. 04, agosto de 1982.)

Antes de Carmen, os conselhos sugeriam que as mulheres suportassem pacientemente a traição do parceiro. Os conselhos de Carmen vão em direção ao enfrentamento da situação: aborde o assunto, mostre o que está em jogo. Ela também 
orienta a interlocutora a mudar o foco da sua ira: a culpa não é da "outra", mas do amante, contrariando o senso comum, entendido por nós como "algo que rege a vida cotidiana e as relações interpessoais" (LAGAZZI, 1988, p. 33). Observamos também que ela chama atenção para o casamento monogâmico como sendo o tradicional brasileiro e, por isso, o sujeito-consulente (moderninha) não deveria ser permissivo em relação à 'pulada de cerca' do marido.

Não podemos discorrer sobre Carmen sem pensar na ironia: recurso linguageiro amplamente utilizado por ela conforme observamos nestas respostas dadas a quatro consulentes:

SD4: Pegue seu título e vá trabalhar noutra cidade. E procure a ajuda de um psicoterapeuta para combater essa vocação de vítima; assim da próxima vez você poderá escolher melhor.

(Seção Aqui, Carmen responde, Ano XI, nº 133, p. 05, outubro de 1972.)

SD5: Não se trata de saber se ele tem outra, mas por que ele considera um sacrifício viver ao seu lado.

(Seção Aqui, Carmem responde, Ano XI, no 122, p. 31, novembro de 1971.)

SD6: E haja autoestima para suportar tanta rejeição.

(Seção Interpessoal, Ano 37, nº 11, p. 196, novembro de 1997.)

SD7: Seria ótimo que seu namorado resolvesse a situação com a antiga mulher, para que ela realmente se transforme em ex.

(Seção Interpessoal, Ano 37, nº 06, p. 22, junho de 1997.)

Trazemos a ironia como fenômeno cujos efeitos sobre quem ouve/lê são paradoxais: podem ser compreendidos (claros) ou incompreendidos (obscuros); provocar riso ou incômodo. Se não há certeza sobre os efeitos que o discurso de um terá sobre o outro, quando se trata da ironia a incerteza é ainda maior, justamente, porque ela tem esse caráter de romper com os processos de significação (ORLANDI, 1986). Carmen, ao se valer da ironia para criticar determinadas condutas, transgredia as convenções da época: nas SDs 4, 5, 6, e 7, por exemplo, chama a atenção para a necessidade de se desfazer um casamento ruim, de se enfrentar os problemas a dois, de cobrar do parceiro determinadas atitudes, de manter a autoestima elevada... 
Nos conselhos dados nas SD8 e SD9, observamos que nas décadas de 1970 e 1980, data em que as cartas foram publicadas na revista Claudia, saberes cristalizados no/pelo patriarcado continuavam circulando e produzindo sentidos. Carmen, em seu dizer, denuncia que a maioria dos maridos ainda "aceita tranquilamente os postulados do sistema patriarcal" (SD8), fazendo uma referência ao fato de que, no dizer do sujeitoconsulente, para o marido um "machão é como um galo", logo, "precisa ter várias galinhas" (jargão este de cunho machista, baseado nos preceitos patriarcais). A esposa, entretanto, "se revolta" com o comportamento do marido, o que nos permite entender que ela se contra identifica com uma formação discursiva patriarcal. Já na SD9, Carmen, em seu dizer, denuncia que o sujeito-consulente continua projetando a imagem de si como a da produtora de varões que, por sua vez, perpetuarão o nome e o patrimônio da família, sendo esta a justificativa da própria "existência feminina". Assim, verificamos que discursos produzidos, na segunda metade do século XX, continuam fazendo circular saberes típicos da família tradicional, ou seja, fundamentada na transmissão do patrimônio, tal qual definiu Roudinesco (2003).

SD8: Você se revolta porque seu marido aceita tranquilamente os postulados do sistema patriarcal: nesse ponto a grande maioria está com ele. (Seção Aqui, Carmen responde, Ano IX, nº 101, p. 112, fevereiro de 1970.)

SD9: Você é preconceituosa a ponto de achar que o decepcionou por só ter lhe dado uma filha mulher, isto é, você continua achando que a única coisa que justifica a existência feminina é produzir varões para darem continuidade ao nome do marido.

(Seção Claudia responde, Ano XXI, nº 246, p. 04, março de 1982.)

Na mesma linha, a próxima sequência discursiva (SD10) faz parte da resposta dada a uma carta publicada no ano 1975, que traz em sua materialidade discursiva uma ressonância, uma memória discursiva sobre a importância da virgindade para as moças de boa família em busca de um casamento, retomando, inclusive, dizeres hegemonizados pela mitologia cristã, de que a castidade e a virgindade são virtudes a serem preservadas antes do matrimônio. Ocorre que o sujeito-consulente se lamenta por ter dado a um homem casado o seu bem mais "precioso": a virgindade. Carmen, por sua vez, diz ser um desalinho a importância dada a valores, a priori, cunhados em outras conjunturas, 
desestabilizando, assim, sentidos cristalizados sobre a virgindade que ressonaram no dizer da interlocutora em A.

SD10: Parece um pouco incrível que esse comportamento corresponda ao de uma universitária que já passou dos 25 .

Na SD11, a traição do marido, no dizer do sujeito-conselheira, é algo intolerável e inadmissível: Carmen não só discorda do sujeito-consulente, como dá outro enfoque ao caso por ela narrado. As antigas "receitas" dadas, com frequência, ao sujeito-consulente de Claudia, de como 'segurar seu homem' começaram, pois, a ser questionadas. A traição do homem precisava ser enfrentada, é como se dissesse: mulheres, parem de esconder o lixo embaixo do tapete! Ocorre que o senso comum justifica os 'casos amorosos' dos homens como mera satisfação sexual, relações não duradouras e sem envolvimento afetivo, não ameaçando o casamento, o que não é regra. A traição tem razões múltiplas: homens e mulheres têm motivações distintas e o futuro de triângulo amoroso não é tão previsível assim. Há, portanto, sentidos sobre a infidelidade estabilizados e regularizados que colocam a mulher, histórica e socialmente, em posição desfavorável ao ato de traição, levando-a à passividade e à aceitação. A tolerância secular para com a infidelidade masculina, tida como inevitável pelo senso comum, assim, é abalada por Carmen:

SD11:

A quem você pensa que está enganando? A mim certamente não é, mas será que ao menos consegue enganar a si própria? Tenho minhas dúvidas. Seu marido admitiu a aventura e você não se zangou: compreende, não tem "nada de ciúmes". Ótimo para ele! A essa altura já sabe que você é "boazinha" e que ele pode abusar à vontade.

(Seção Carmen responde, Ano XXI, nº 251, p. 04, agosto de 1982.)

Na SD 12, o sujeito-conselheira, em seu dizer, alerta que o sujeito-consulente não deve se iludir com as mentiras do marido de que o caso terminou. Carmen, ao responder ao sujeito-consulente, que ocupa a posição de esposa de um homem que "tem aventuras constantes" e não conversa nem dorme mais com ela, diz da superficialidade de uma relação que só existe "na aparência”, não tem substância, é só invólucro, objetificada, portanto. Acreditar que o triângulo amoroso se desfez funcionaria, assim, como uma 
forma de apagamento da permanência do adultério, manifestado por meio "dos silêncios, de práticas que o atestam, mas que não se expõem como tal (ORLANDI, 2008, p. 69).

SD12: Não se engane com mentiras [...] para não destruir um vínculo que já só existe na aparência, você destrói a si mesma.

$\mathrm{Na}$ última sequencia analisada (SD13) por nós, Carmen questiona o amor vivido pelo sujeito-consulente, comparando tal amor a um mito, fruto, portanto, da sua imaginação, visto que o casamento não mais se consuma. Critica, com suas indagações, a resignação do sujeito-consulente, a sua predisposição de se manter ao lado de um homem que não mais a deseja, não a estimulando, portanto, a tentar "consertar" o casamento, tido comumente como sendo "para-sempre".

SD13: Você ama o quê, ama como? [...] De que se alimenta esse amor? [...] você ficará sempre presa ao mito do grande amor de sua vida...

Conforme pudemos verificar, a seção de cartas traz em seu conteúdo histórias de vida, mais ou menos similares, que sempre trarão sentidos já estabilizados, mas que também farão surgir outros sentidos, constituindo-se como um espaço de tensão entre o mesmo e o diferente que afetará de alguma forma as leitoras de Claudia. E nesse jogo entre o mesmo e o diferente, Carmen, em sua posição de conselheira, desestabilizou sentidos: não dizendo o de sempre, rompeu com construídos cristalizados e apresentou as suas leitoras novos significados para o casamento.

\section{Considerações finais}

As revistas femininas colocam em circulação discursos estabilizados que, como tal, homogeneizaram sentidos, entre outros, sobre a posição do homem e a posição da mulher, sobre o que cabe a um e o que cabe a outra, sem que a hierarquia entre uns e umas tenha sido desconsiderada. Assim, o casamento foi sendo ressignificado e os sentidos para as posições esposas e amantes também.

O discurso, produzido pelas primeiras revistas femininas brasileiras e por Claudia, durante a segunda metade do século XX, conforme verificamos, se sustentaria a partir de uma memória social do feminino que é atravessada pelas ideologias patriarcal e católica, visto que difundiram o machismo, logo, a submissão da mulher. 
Afinal, o discurso, em circulação nessas publicações, participou da formação de um imaginário sobre as relações e as posições de homens e mulheres.

Claudia diz de um lugar e diz de determinadas circunstâncias, conjecturas sócio históricas, porque os discursos são produzidos em certas condições que, por sua vez determinam o sentido (PÊCHEUX, [1975] 2014). Então, o dizer de Claudia não é deslocado do seu tempo, como não é deslocado da imagem que faz de suas leitoras. Assim, ao dizer, tenta antecipar-se sobre o que suas leitoras gostariam de ler a partir das imagens projetadas delas. Porém, isso não impede a revista de reformular, transformar, de dizer diferente, pois, todo discurso é marcado por contradições. Claudia vai, assim, marcando suas contradições, porque sua filiação tanto pode ser a uma matriz machista quanto feminista. Considerando ou não os 'furos' (entrada à revelia), dos quais nenhum arquivo está isento durante seu processo de constituição (DELA-SILVA e DIAS, 2015), Carmen da Silva mereceu nosso destaque: não só porque foi uma importante articulista de Claudia por mais de 20 anos, mas também porque teve relevante papel enquanto conselheira da seção destinada a responder as cartas enviadas ao "consultório sentimental", rompendo com o padrão de resposta e se aproximamdo das consulentes: as tratava pelo nome, ou por adjetivos como querida, amiga; dava-lhes 'bronca', desejava sorte e se dizia torcer por um desfecho feliz. Carmen, em seu dizer, não se contentou em ser complacente com a dor alheia, colocava o 'dedo na ferida', contrariando expectativas.

Carmen era uma feminista e dizia desse lugar, contribuindo para que os saberes circulantes em Claudia partissem de outra matriz que não a machista. Não queremos afirmar, entretanto, que a conselheira rompeu completamente com ela, porque, afinal, todo discurso é marcado por contradições. Entretanto, vislumbramos nos dizeres contraditórios de Carmen da Silva enfrentamentos, escapes, furos que fazem surgir novas significações e emergir no fio discursivo sentidos outros não tão esperados. "As fronteiras sempre móveis da produção de sentidos" (MARIANI, 1999, p. 49) levaram a imprensa feminina permitir que as mulheres "iniciassem o processo de questionamento do lugar que ocupavam na sociedade" porque, mesmo moldando comportamentos cordatos, apresentou a elas "novas oportunidades de expressão e afirmação enquanto sujeitos autônomos" (ARAS e MARINHO, 2012, p. 103), se configurando também em um espaço de resistência. 


\section{Referências}

ALI, F. A arte de editar revistas. São Paulo/SP: Companhia Editora Nacional, 2009.

ALTHUSSER, L. Ideologia e aparelhos ideológicos do Estado. Lisboa: Presença, 1974.

ALVES, C; CAETANO, A. e FREITAS, A. C. Jornal das Moças: ensino, mídia e discurso. NAMID/UFPB. Ano XII, n. 02. Fevereiro/2016. Disponível em periodicos.ufpb.br/index.php/ tematica/article/download/27807/14941. Acesso em $13 / 05 / 2017$.

ANTUNES, C. M. S. A. A construção do ethos nas cartas do editor de revistas: o valor dos lugares. Rio de Janeiro/RJ: UFRJ, 2016.

ARAS, L. M. B. e MARINHO, S. R. A imprensa feminina: normatização da conduta feminina nos jornais para mulheres (Bahia, 1860-1917). Historia, ISSN 1519-8502, EISSN 2238-5541, Rio Grande/RS, 2012. Disponível em https://periodicos.furg.br/hist/article/view/2591. Acesso em: 04/01/2018.

AZEVEDO, L. H. de. A construção da nova mulher nas revistas Querida e Claudia (décadas de 1960 e 1970). Tese de Doutorado - Faculdade de Ciências e Letras de Assis - Universidade Estadual Paulista, 2009. Disponível em https://repositorio.unesp.br/handle/11449/93348. Acesso em 10/12/2017.

BASSANEZI, C. B. Virando as páginas, revendo as mulheres: revistas femininas e relações homem-mulher, 1945-1964. Rio de Janeiro/RJ: Civilização Brasileira, 1996.

BITTELBRUN, G.V. A beleza da mulher nas páginas da Revista Claudia desde a década de 1960: a identidade atribuída à figura feminina. X Congresso de Ciências da Comunicação na Região Sul. Blumenau, 2009. Disponível em: http://www.intercom.org.br/papers/regionais/sul2009/lista_area_DT07.htm. Acesso em 03/03/2018.

BUITONI, D. H. S. Mulher de Papel: a representação da mulher na imprensa feminina brasileira. São Paulo/SP: Edições Loyola, 1986. 
CAZARIN, A. E. e MENEZES, E. S. A mídia e o golpe de 1964: revista O Cruzeiro como aliada do discurso das forças militares. Conexão Letras. A noção de arquivo em Análise do Discurso: relações e desdobramentos/Programa de Pós-Graduação do Instituto de Letras da UFRGS - Vol. 9, n. 11. Porto Alegre/RS: Universidade Federal do Rio Grande do Sul, 2014. DOI: https://doi.org/10.22456/2594-8962.55145. Acesso em: 20/05/2017.

COELHO, A. e DAVID, F. Mulheres em revista: o jornalismo feminino no brasil. Secretaria Especial de Comunicação Social. Rio de Janeiro - O Cruzeiro - A maior e melhor revista da América Latina, 2002. Disponível em: www.rio.rj.gov.br/dlstatic/10112/4204434/4101415/ memoria4.pdf. Acesso em: $\underline{04 / 06 / 2018 .}$

CORRÊA, T. S. Termina aqui "A Arte de Ser Mulher". IN: CIVITA, L. T. (Org.). O Melhor de Carmen da Silva. Rio de Janeiro/RJ: Rosa dos Tempos, 1994.

CRESTANI, J. L. O perfil editorial da revista a estação: jornal ilustrado para a família. Revista da ANPOLL, 2008. DOI: https://doi.org/10.18309/anp.v1i25.67.

DELA-SILVA, S. C. O acontecimento discursivo da televisão no Brasil: a imprensa na constituição da TV como grande mídia. Tese de doutorado. Campinas/SP, 2008. Disponível em: http://repositorio.unicamp.br/jspui/handle/REPOSIP/271055. Acesso em 28/06/2016.

DELA-SIVA, S e DIAS, J. P. Felicidade, um arquivo. Sobre a noção de arquivo e o seu funcionamento no discurso da/na mídia. In: INDURSKY, F.; LEANDRO- FERREIRA, L. M. A. Jornalístico escreve a história do presente. SEAD 1969-2009: memória e história na/da análise do discurso. Porto Alegre/RS, 2009. Disponível em: http://anaisdosead.com.br/6SEAD/SIMPOSIOS/ OArquivoDaFelicidade.pdf. Acesso em: 20/07/2016.

DUARTE, C.L. Imprensa Feminina e Feminista no Brasil: Século XIX: dicionário ilustrado. Belo Horizonte: Autêntica editora, 2016.

FERREIRA, L. M. A. Discurso, imagem e redes de sentido: quando o acontecimento jornalístico escreve a história do presente. SEAD 1969-2009: memória e história na/da análise do discurso. Porto Alegre/RS, 2007. Disponível em: http://anaisdosead.com.br/4SEAD/SIMPOSIOS/ LuciaMariaAlvesFerreira.pdf. Acesso em: 13/08/2017.

FERREIRA, V. R. C.; RÊEGO, A. R. B. L. Eis a Mulher Contemporânea: a revista Claudia e a representação do feminino. XIV Congresso de Ciências da Comunicação na Região 
Nordeste. $\quad$ Recife/PE, $2012 . \quad$ Disponível em: http://www.intercom.org.br/papers/regionais/nordese2012/ resumos/R32-1286-1.pdf. Acesso em: 29/07/2016.

GRIGOLETTO, E. Do lugar social ao lugar discursivo: o imbricamento de diferentes posições-sujeito. SEAD, 2005. Disponível em: http://www.ufrgs.br/analisedodiscurso/anaisdosead/2SEAD/ SIMPOSIOS/EvandraGrigoletto.pdf. Acesso em: 04/05/2015.

INDURSKY, F. A memória na cena do discurso. In: INDURSKY, F.; MITTMANN, S.; LEANDRO-FERREIRA, M.S. (Org.). Memória e história na/da análise do discurso. Campinas/SP: Mercado das letras, 2011.

INDURSKY, F. O trabalho discursivo do sujeito o trabalho discursivo do sujeito entre o memorável e a deriva. Universidade Federal de Rio Grande do Sul, 2013. Disponível em: http://revistas.filo.uba.ar/index.php/sys/article/view/118. Acesso em 07/10/2016.

JARDIM, T. S. e BRANDÃO, I. B. S. Breve histórico da imprensa no Brasil: Desde a colonização é tutelada e dependente do Estado. Revista Eletrônica de Relações Internacionais do Centro Universitário Unieuro ISSN: 1809-1261 UNIEURO, Brasília, número $14, \quad 2014, \quad$ p. 131-171. Disponível e: www.unieuro.edu.br/.../Iolanda\%20Brandão\%20e\%20Trajano\%20Jardim\%20(6). pdf. Acesso em: 03/11/2017.

LAGAZZI, S. M. O desafio de dizer não. Campinas/SP: Pontes, 1988.

MAGALHÃES, B. Trabalho, Gênero e Educação. In: MAGALHÃES, Belmira; BERTOLDO, Edna (org.). Trabalho, Educação e Formação Humana. Maceió: Edufal, 2005.

MAGALHÃES, B. Lógica capitalista e patriarcado. In: Gilmaísa M Costa; Edlene Pimentel; Norma Alcântara; Reivan Souza. (Org.). Crise Contemporânea, Desafios do Conhecimento e Lutas Sociais. Maceió: Edufal, 2017, v. 1, p. 1-354.

MARIANI, B. S. C. Discurso e instituição: a imprensa. Revista Rua, vol. 5, no. 1. Campinas: LABEURB, 1999, p. 47 a 61. DOI: https://doi.org/10.20396/rua.v5i1.8640651. Acesso em 03/04/2016.

MIRA, M. C. O leitor e a banca de revistas: a segmentação da cultura no século XX. São Paulo/SP: Olho d'Água/Fapesp, 2001. 
NOGUEIRA, D. C. L. Imprensa feminina e consumo: Jornalismo e publicidade na revista Claudia. Projeto experimental. Universidade Federal de Juiz de Fora/MG. Faculdade de Comunicação, 2003.

NORA, P. O retorno do fato. In: LE GOFF, Jacques \& NORA, Pierre. História: Novos Problemas, Rio de Janeiro/RJ: F. Alves, 1976.

ORLANDI, E. P. Desconstrução e construção do sentido: um estudo da ironia. In: Série Estudos, Faculdades Integradas de Uberaba, nº 12, p.66-96, 1986.

ORLANDI, E. P. As Formas do Silêncio. Campinas/SP: editora da UNICAMP, 2007.

PÊCHEUX, M. Ler o arquivo hoje. IN: ORLANDI, E.P. (Org.). Gestos de leitura. Campinas, SP: editora da UNICAMP, 1997.

PÊCHEUX, M. Papel da memória. IN: ACHARD, Pierre et al. Papel da Memória. Campinas/SP: editora da UNICAMP, 1999.

PÊCHEUX, M. [1969] Análise Automática do Discurso. In: GADET, F. \& HAK, T.(Org.). Por uma análise automática do discurso. Campinas/SP: editora da UNICAMP, 2014.

PÊCHEUX, M e FUCHS, C. [1975] A propósito da Análise Automática do Discurso. IN: GADET \& HAK (Org). Por uma análise automática do discurso. Campinas/SP: editora da UNICAMP, 2014.

PORTILHO, R. "Onde está o jornalismo?" - Uma análise da imprensa feminina a partir de Claudia (1961 e 1968). XXXII Congresso Brasileiro de Ciências da Comunicação. Curitiba/PR, 2009.2 Disponível em: http://www.intercom.org.br/papers/nacionais/2009/resumos/R4-1165-1.pdf. Acesso em 25/09/2017.

REBELO, A.C.T. Mulher de Nova, Mulher de Fases: o jogo da vida nas páginas de Cosmopolitan Brasil. Dissertação. RJ: UERJ, 2017.

ROUDINESCO, E. A família em (des)ordem. Rio de Janeiro/RJ: Jorge Zahar Editor, 2003. 
SCALZO, M. Jornalismo de revista. São Paulo/SP: Contexto, 2004.

SODRÉ, N. W. História da Imprensa no Brasil. Rio de Janeiro/RJ: Martins Fontes, 1983.

VENTURINI, M. C. O sujeito porta-voz é sempre um nós em construção? São Paulo/SP: Alfa 56 (1): 293-308, 2012.

VIDUTTO, M.C.S.B. Design em revista feminina - um olhar sobre Claudia. 204f.: il.; 30 cm. Orientadora: Gisela Beluzzo de Campos. Dissertação (Mestrado em Design) Universidade Anhembi Morumbi, São Paulo/SP, 2010. Disponível em: http://bdtd.ibict.br/vufind/Record/ANHE_9a806d74cf83bb086cf0ca6e192b4aeb. Acesso em: 14/07/2017.

Sites:

HANCIAU, N. Carmen da Silva.com.br.

carmendasilva.com.br/site/php/content.php?id=11. s/a. Acesso em: 20/11/2018.

MELLO, D. L. F. de. Falando sobre mídia: revista.

plugcitarios.com/blog/2013/10/18/falando-midia-revista/ Acesso em: 30/04/2017.

MIRANDA, J. Revistas femininas nos anos 50 e 60 (A mulher no mundo machista). www.sitedecuriosidades.com/curiosidade/revistas-femininas-nos-anos-50-e-60-amulher-no-mundo-machista.html, s/a. www.revistaprosaversoearte.com/mulher-nomundo-machista-as-revistas-femininas-nos-anos-50-e-60/. Acesso em: 05/03/2018.

MOURA, J. Universo Feminino. Canal da Imprensa. unasp-ec.com/canaldaimprensa2/ PortalAntigo/canalant/foco/quarent5/foco8.htm. Acesso em 05/05/2017.

REIS, M. História da revista Claudia. emfechamento.com.br/2012/03/historia-darevistaclaudia.html\#. Acesso em: 30/04/2017.

Revistas:

REVISTA REALIDADE. Editorial. São Paulo/SP: Editora Abril, nº11, fevereiro, 1967.

SILVA, C. da. Consultório Sentimental. Revista Realidade, São Paulo/SP: Editora Abril, $\mathrm{n}^{\circ} 10$, janeiro, 1967.

Recebido em fevereiro de 2019.

Aprovado em abril de 2019. 